\title{
THE TOTAL SYNTHESIS OF NOCARDICIN A
}

\author{
William V. Curran,* Martin L. Sassiver, Adma S. Ross, \\ Thomas L. Fields and James H. Boothe
}

\begin{abstract}
Chemical Department, Infectious Disease Therapy Section, American Cyanamid Co., Medical Research Division, Lederle Laboratories, Pearl River, New York, 10965 U.S.A.
\end{abstract}

(Received for publication December 22, 1981)

We report here a total synthesis of nocardicin A. The antibiotic was obtained as a mixture of diastereoisomers that possessed approximately one quarter of the antibacterial activity of the naturally occurring material.

Recently a new $\beta$-lactam antibiotic, nocardicin A, has been reported. ${ }^{1,2)}$ This is the first example of a monocyclic $\beta$-lactam derivative having antimicrobial activity. We report here the synthesis of this antibiotic. Two syntheses of nocardicin A have thus far been reported. ${ }^{3,4}$ The synthesis of a hydroxymethyl analog has also recently appeared..$^{5)}$

\section{A. Synthetic Strategy}

The synthesis of nocardicin A can be visualized as a three part problem involving 1) synthesis of the side chain acid containing homoserine linked at the para position to the oxime derivative of phenyl-

Scheme 1.

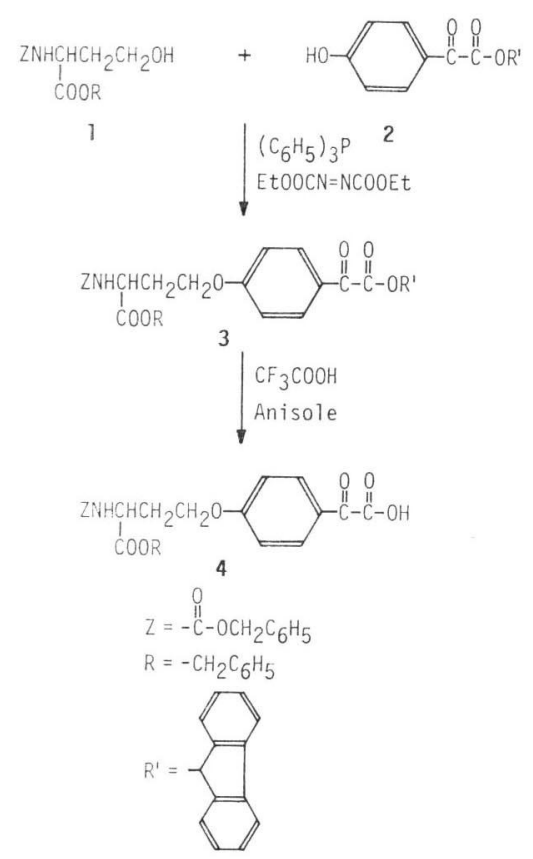

Scheme 2. Synthesis of the $\beta$-lactam moiety.

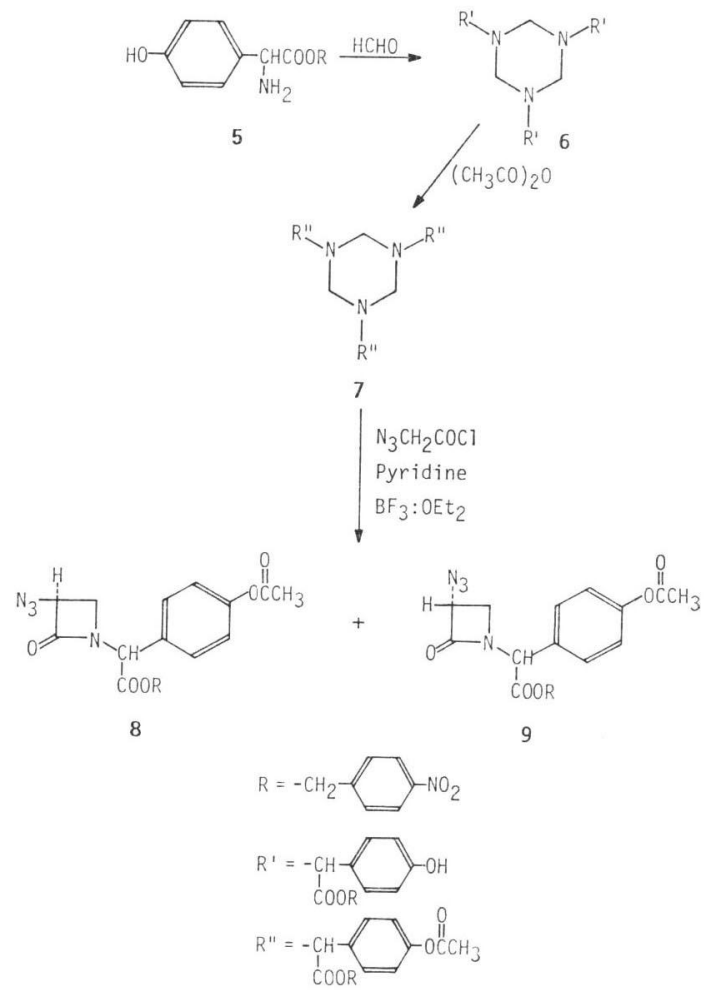


glyoxylic acid, 2) synthesis of the $\beta$-lactam moiety containing the D-p-hydroxyphenylglycine and 3) coupling of the two suitably protected parts of the molecule followed by removal of the protecting groups to give the desired nocardicin A.

\section{B. Synthesis of the Side Chain Acid (Scheme 1)}

Carbobenzoxy- $( \pm)$-homoserine benzyl ester $\mathbf{1}^{\mathbf{b})}$ was coupled with the fluorenyl ester of $p$-hydroxyphenylglyoxylic acid $\mathbf{2}^{\text {7) }}$ using diethyl azodicarboxylate and triphenylphosphine to afford compound 3 which was readily converted to the side chain acid $\mathbf{4}$ by reaction with trifluoroacetic acid and anisole.

\section{Synthesis of the $\beta$-Lactam Moiety (Scheme 2)}

The starting material for this synthesis was the commercially available Dane salt of D-p-hydroxyphenylglycine which was converted to the $p$-nitrobenzyl ester by treatment with $p$-nitrobenzyl bromide in dimethylformamide. Acid hydrolysis to the aminoester $\mathbf{5}$ followed by treatment with formaldehyde afforded the triazine 6 . This compound was acetylated to give the fully protected derivative 7 which was converted to a diastereomeric mixture of the $\beta$-lactams 8 and 9 by reacting with boron trifluoride etherate, pyridine, and azidoacetyl chloride. ${ }^{8>}$ This mixture which was composed of a $2: 1$ ratio (8 and $\mathbf{9}$ ) in favor of the desired compound, as shown by proton magnetic resonance spectroscopy, was purified by high pressure liquid chromatography and converted to the corresponding amino compounds (10) by treating with hydrogen sulfide and triethylamine (see Scheme 3).

A similar route to some phthalimidonocardicinic acid compounds has been reported by KAMIYA et al. ${ }^{\text {) }}$

Table 1 . In vitro activity of nocardicin $\mathrm{A}$, natural and synthetic.

\begin{tabular}{|c|c|c|c|}
\hline \multirow{2}{*}{ Culture } & \multirow{2}{*}{$\begin{array}{c}\text { Strain } \\
\text { designation }\end{array}$} & \multicolumn{2}{|c|}{$\mathrm{MIC}(\mathrm{mcg} / \mathrm{ml})$} \\
\hline & & $\underset{\text { A }}{\text { Nocardicin }}$ & $\begin{array}{c}\text { Synthetic } \\
\text { sample }\end{array}$ \\
\hline $\begin{array}{l}\text { Pseudomonas } \\
\text { aeruginosa }\end{array}$ & $12-4-6$ & 64 & 256 \\
\hline $\begin{array}{l}P \text {. } \\
\text { aeruginosa }\end{array}$ & UCS 76-18 & 16 & 64 \\
\hline $\begin{array}{l}\text { Serratia } \\
\text { marcescens }\end{array}$ & $\mathrm{F}-35$ & 64 & 64 \\
\hline Prot. mirabilis & OSY 75-1 & 4 & 16 \\
\hline Prot. mirabilis & $\# 4671$ & 4 & 16 \\
\hline Prot. mirabilis & W-75-2 & 4 & 16 \\
\hline E. coli & ESS $22-31$ & 0.5 & 2 \\
\hline $\begin{array}{l}\text { Micrococcus } \\
\quad \text { luteus }\end{array}$ & PCI-1001 & 64 & 256 \\
\hline
\end{tabular}

Scheme 3. Synthesis of nocardicin A.
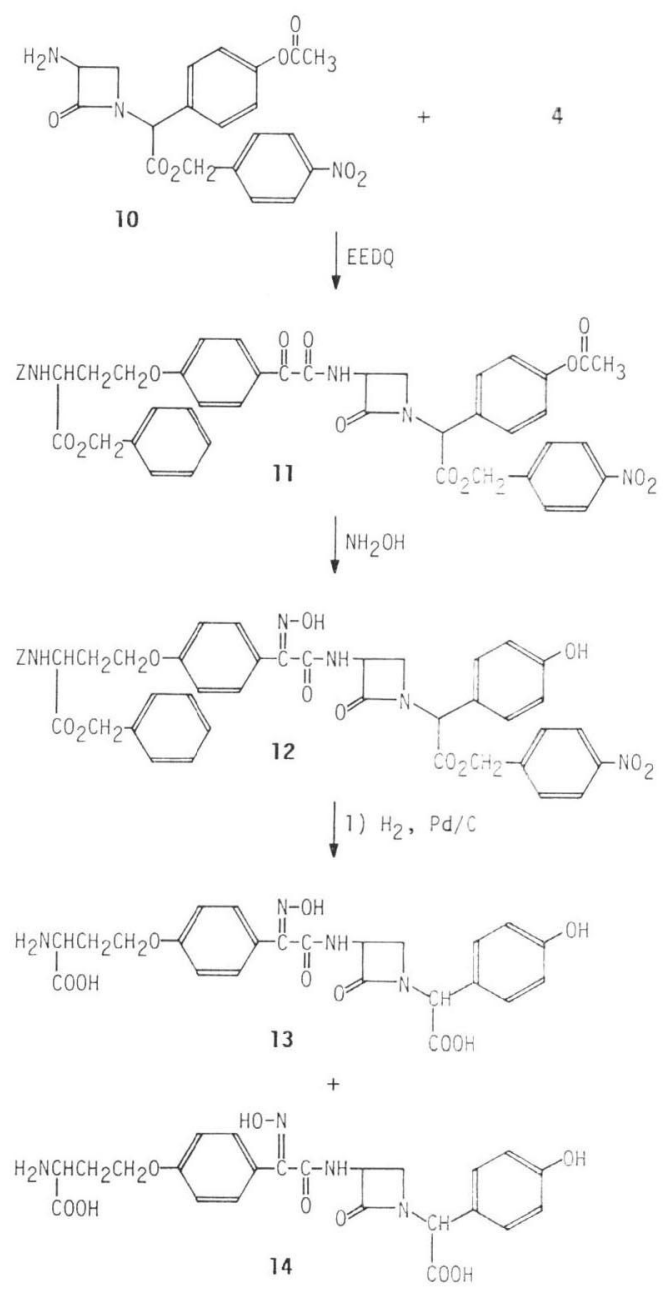


\section{Synthesis of Nocardicin A (Scheme 3)}

The protected side chain acid $\mathbf{4}$ was coupled with the 3-aminonocardicinic acid derivative $\mathbf{1 0}$ using EEDQ (ethyl 1,2-dihydro-2-ethoxy-1-quinolinecarboxylate) to give the desired product (11) which was purified by column chromatography. Treatment of compound $\mathbf{1 1}$ with hydroxylamine and pyridine at $60^{\circ} \mathrm{C}$ cleaved the acetate protecting group of the phenol moiety and gave the oxime 12. Catalytic hydrogenation of compound $\mathbf{1 2}$ gave nocardicin A (13) as a mixture of diastereoisomers along with some nocardicin B (14) as shown by proton magnetic resonance spectroscopy.

The in vitro activity of the synthetic compound was approximately one quarter of that exhibited by the natural antibiotic as shown in Table 1.

\section{Experimental}

9'-Fluorenyl $p$-Hydroxyphenylglyoxylate (2)

A solution of diazofluorene $(9.65 \mathrm{~g})$ in $125 \mathrm{ml}$ of ethyl acetate was added in several portions to $p$ hydroxyphenylglyoxylic acid $\left.{ }^{7}\right)(8.3 \mathrm{~g})$ in $75 \mathrm{ml}$ of ethyl acetate and the solution was stored overnight at room temperature. The solution was extracted with dilute sodium bicarbonate, dried $\left(\mathrm{MgSO}_{4}\right)$ and concentrated to give $10.5 \mathrm{~g}$ of product: m.p. $172 \sim 174^{\circ} \mathrm{C}$.

Anal. Calcd. for $\mathrm{C}_{21} \mathrm{H}_{14} \mathrm{O}_{4}$ : C 76.35, $\mathrm{H} 4.27$.

Found: $\quad$ C 76.29, $\mathrm{H} 4.86$.

1,2-Dibenzyl-4-(9-fluorenyl)-2-carboxyamino-4-( $p$-carboxycarbonylphenoxy)-( \pm )-butyrate (3)

A solution of compound $2(0.991 \mathrm{~g})$, carbobenzoxy- $( \pm)$-homoserine benzyl ester ${ }^{8)}(1.03 \mathrm{~g})$, triphenylphosphine $(0.787 \mathrm{~g})$ and diethyl azodicarboxylate $(0.522 \mathrm{~g})$ in $20 \mathrm{ml}$ of tetrahydrofuran was stirred at room temperature for 48 hours under nitrogen. The solution was evaporated to dryness, triturated with ether and filtered. The filtrate was evaporated to a syrup which was chromatographed on silica gel using chloroform to afford $1.26 \mathrm{~g}$ of product as a foam: NMR (DMSO- $\left.d_{8}\right) \delta 4.18\left(\mathrm{~m}, 3 \mathrm{H}, \mathrm{CH}_{2} \mathrm{O}+\right.$ -CHO), 5.04 (s, 2H, $\left.\phi \mathrm{CH}_{2}-\right), 5.16\left(\mathrm{~s}, 2 \mathrm{H}, \phi \mathrm{CH}_{2}-\right.$ ).

Anal. Calcd. for $\mathrm{C}_{40} \mathrm{H}_{38} \mathrm{NO}_{8}$ : C 73.27, $\mathrm{H}$ 5.07, N 2.14.

Found: $\quad$ C 73.04, H 5.30, N 2.21.

1,2-Dibenzyl-2-carboxyamino-4-( $p$-carboxycarbonylphenoxy)-(+)-butyrate (4)

A solution of $810 \mathrm{mg}$ of fluorenyl ester (3) dissolved in anisole $(1.82 \mathrm{ml})$ was cooled in an ice bath, and $8 \mathrm{ml}$ of chilled trifluoroacetic acid was added with stirring. After 10 minutes in the cold, the acid was removed by high vacuum evaporation $\left(25^{\circ} \mathrm{C}\right)$. Finally, pumping was continued for about- 40 minutes while the flask was immersed in room temperature water. The residue was dissolved in $15 \mathrm{ml}$ of ether and extracted with $10 \mathrm{ml}$ of water containing $180 \mathrm{mg}$ of sodium bicarbonate (chilled). Centrifugation was required to separate the phases. The aqueous layer was acidified to $\mathrm{pH} 2$ in the cold and extracted with ether. The ether was dried and evaporated to $440 \mathrm{mg}$ of a syrup; NMR (DMSO- $d_{8}$ ) $\delta 7 \sim 8(\mathrm{~m}$, $14 \mathrm{H}, \phi), 5.02\left(\mathrm{~s}, 2 \mathrm{H}, \phi \mathrm{CH}_{2}-\right), 5.16\left(\mathrm{~s}, 2 \mathrm{H}, \phi \mathrm{CH}_{2}-\right.$ ).

Anal. Calcd. for $\mathrm{C}_{27} \mathrm{H}_{25} \mathrm{NO}_{8}$ : C 65.98, H 5.13, N 2.85.

Found:

C 66.36, H 5.36, N 2.73 .

$N$-(2-Methoxycarbonyl-1-methylvinyl)-D-4-hydroxyphenylglycine- $p$-nitrobenzyl Ester

A solution of $21.6 \mathrm{~g}(0.1 \mathrm{~mole})$ of $p$-nitrobenzyl bromide in $75 \mathrm{ml}$ dimethylformamide was added at room temperature in small portions over 40 minutes to a stirred solution of $28.7 \mathrm{~g}(0.1 \mathrm{~mole})$ of $\mathrm{N}$ (2-methoxycarbonyl-1-methylvinyl)-D(-)-4-hydroxyphenylglycine in $200 \mathrm{ml}$ dimethylformamide. After stirring at room temperature overnight, the mixture was poured into 1.6 liter of ice water and extracted into $8 \times 200 \mathrm{ml}$ ethyl acetate. The ethyl acetate was washed with water and saturated sodium chloride. Evaporation gave a pale yellow oil which was crystallized from ethyl acetate - hexane to afford $21 \mathrm{~g}$ $(52 \%)$ of a white, crystalline solid, m.p. $132 \sim 134^{\circ} \mathrm{C}:[\alpha]_{\mathrm{D}}^{23}+214 \pm 2^{\circ}\left(c 0.553, \mathrm{CH}_{3} \mathrm{OH}\right): \mathrm{IR}\left(\mathrm{KBr}, \mathrm{cm}^{-1}\right)$ 1742, 1655: NMR $\left(\mathrm{CDCl}_{3}+\mathrm{DMSO}-d_{6}\right) \delta 9.46(\mathrm{~d}, 1 \mathrm{H}, \mathrm{NH}), 9.12(\mathrm{~s}, 1 \mathrm{H}, \mathrm{OH}), 8.12 \& 7.34\left(\mathrm{dd}, 4 \mathrm{H}, \mathrm{NO}_{2}-\right.$ $A r, J=10 \mathrm{~Hz}), 7.20+6.84(\mathrm{dd}, 4 \mathrm{H}, \mathrm{HO} A r, J=11 \mathrm{~Hz}), 5.28\left(\mathrm{~m}, 3 \mathrm{H}, \mathrm{OCH}_{2}+\mathrm{NCH}\right), 4.57(\mathrm{~s}, 1 \mathrm{H},=\mathrm{CH})$, $3.66\left(\mathrm{~s}, 3 \mathrm{H}, \mathrm{OCH}_{3}\right), 1.83\left(\mathrm{~s}, 3 \mathrm{H}, \mathrm{CCH}_{3}\right)$. 
$\begin{array}{ll}\begin{array}{l}\text { Anal. Calcd. for } \mathrm{C}_{20} \mathrm{H}_{20} \mathrm{~N}_{2} \mathrm{O}_{7}: \\ \text { Found: }\end{array} & \text { C 60.00, H 5.03, N } 7.00 .22, \mathrm{H} 5.12, \mathrm{~N} 7.12 .\end{array}$

D-4-Hydroxyphenylglycine $p$-Nitrobenzyl Ester (5)

$N$-(2-Methoxycarbonyl-1-methylvinyl)-D(-)-4-hydroxyphenylglycine $p$-nitrobenzyl ester (70 g) was dissolved in $300 \mathrm{ml}$ acetone and $200 \mathrm{ml}$ water. Over 40 minutes, $170 \mathrm{ml} 1 \mathrm{~N} \mathrm{HCl}$ was added dropwise, with stirring. Acetone was evaporated, and the aqueous residue was stirred with $100 \mathrm{ml}$ ethyl acetate, chilled, and filtered. The filter cake was washed thoroughly with diethyl ether to give $42 \mathrm{~g}(81 \%)$ of a white solid. $[\alpha]_{\mathrm{D}}^{23}-58^{\circ} \pm 1\left(c 0.833, \mathrm{CH}_{3} \mathrm{OH}\right)$ : IR $\left(\mathrm{KBr}, \mathrm{cm}^{-1}\right) 1760,1702$ : NMR (DMSO- $\left.d_{6}\right) \delta 8.17$ $7.48\left(\mathrm{dd}, 4 \mathrm{H}, \mathrm{NO}_{2} A r, J=12 \mathrm{~Hz}\right), 7.22+6.73(\mathrm{dd}, \mathrm{HO} A r, J=10 \mathrm{~Hz}), 5.25\left(\mathrm{~s}, 2 \mathrm{H}, \mathrm{OCH}_{2}\right), 4.55(\mathrm{~s}, 1 \mathrm{H}$, $\mathrm{NCH})$.

Anal. Calcd. for $\mathrm{C}_{15} \mathrm{H}_{14} \mathrm{~N}_{2} \mathrm{O}_{5}$ : C 59.60, H 4.67, N 9.27.

Found: $\quad$ C $59.24, \mathrm{H} \mathrm{4.74,} \mathrm{N} 9.02$.

1,3,5-Tris-[D(-)-1-(4-nitrobenzyloxycarbonyl) -1-(4-hydroxyphenyl) methyl] perhydro-1,3,5-triazine (6)

$\mathrm{D}(-)-4$-Hydroxyphenylglycine $p$-nitrobenzyl ester (5) (42 g, 0.14 mole) was slurried in $250 \mathrm{ml}$ tetrahydrofuran and $17 \mathrm{ml}(0.17$ mole) $40 \%$ aqueous formaldehyde was added. The resulting solution was stirred overnight at room temperature, evaporated to $100 \mathrm{ml}$ and $350 \mathrm{ml}$ methylene chloride was added. After extraction with water and saturated sodium chloride, the solution was dried over magnesium sulfate and evaporated to give $44 \mathrm{~g}(100 \%)$ of a foam which dried as a glass. $[\alpha]_{\mathrm{D}}^{23}-63^{\circ}\left(c 0.757, \mathrm{CH}_{3} \mathrm{OH}\right)$ : IR $\left(\mathrm{KBr}, \mathrm{cm}^{-1}\right)$ 1750: NMR (DMSO- $\left.d_{6}\right) \delta 9.49(\mathrm{~s}, 3 \times 1 \mathrm{H}, \mathrm{ArOH}), 8.12 \& 7.37$ (dd, $4 \mathrm{H}, \mathrm{NO}_{2} A r, J=11$ $\mathrm{Hz}), 7.12+6.65(\mathrm{dd}, 3 \times 4 \mathrm{H}, \mathrm{HO} A r, J=11 \mathrm{~Hz}), 5.11\left(\mathrm{~s}, 3 \times 2 \mathrm{H}, \mathrm{OCH}_{2}\right), 4.50(\mathrm{~s}, 3 \times 1 \mathrm{H}, \mathrm{NCH}), 3.35(\mathrm{~s}, 3 \times$ $\left.2 \mathrm{H}, \mathrm{CH}_{2} \mathrm{~N}\right)$.

Anal. Calcd. for $\mathrm{C}_{48} \mathrm{H}_{42} \mathrm{~N}_{8} \mathrm{O}_{15}$ : C 61.14, H 4.49, N 8.91.

Found: $\quad$ C 60.77, H 5.02, N 7.95.

1,3,5-Tris-[D (-)-1-(4-nitrobenzyloxycarbonyl)-1-(4-acetoxyphenyl) methyl] perhydro-1,3,5-triazine (7)

1,3,5-Tris-[D(-)-1-(4-nitrobenzyloxycarbonyl) -1-(4-hydroxyphenyl) methyl] perhydro-1,3,5-triazine (6) $(20.0 \mathrm{~g}) 60 \mathrm{ml}$ acetic anhydride, and $150 \mathrm{ml}$ pyridine were heated on a steam bath for 10 minutes. The solution was evaporated to an oil which was codistilled several times with toluene. The residue was washed with saturated sodium bicarbonate, water, and saturated sodium chloride, dried over magnesium sulfate, filtered through Magnesol, and evaporated to a pale yellow oil which was crystallized from ethyl acetate - hexane to give $10.2 \mathrm{~g}(45 \%)$ of white crystals, m.p. $103 \sim 105^{\circ} \mathrm{C} . \quad[\alpha]_{\mathrm{D}}^{23}-33^{\circ} \pm 1(c 0.78$, $\left.\mathrm{CH}_{3} \mathrm{OH}\right):$ IR $\left(\mathrm{KBr}, \mathrm{cm}^{-1}\right)$ 1750: NMR $\left(\mathrm{CDCl}_{3}\right) \delta 8.12 \& 7.36\left(\mathrm{dd}, 3 \times 4 \mathrm{H}, \mathrm{NO}_{2} A r, J=11 \mathrm{~Hz}\right), 7.18 \&$ $6.97(\mathrm{dd}, 3 \times 4 \mathrm{H}, \mathrm{O} A r, J=12 \mathrm{~Hz}), 5.08\left(\mathrm{~s}, 3 \times 2 \mathrm{H}, \mathrm{OCH}_{2}\right), 4.62(\mathrm{~s}, 3 \times 1 \mathrm{H}, \mathrm{NCH}), 3.62\left(\mathrm{~s}, 3 \times 2 \mathrm{H}, \mathrm{CH}_{2} \mathrm{~N}^{2}\right.$, $2.32\left(\mathrm{~s}, 3 \times 3 \mathrm{H}, \mathrm{CH}_{3} \mathrm{C}=\mathrm{O}\right)$.

Anal. Calcd. for $\mathrm{C}_{54} \mathrm{H}_{48} \mathrm{~N}_{6} \mathrm{O}_{18}$ : C 60.67, H 4.53, N 7.86.

Found: $\quad$ C $60.38, \mathrm{H} 4.35, \mathrm{~N} 7.80$.

D(-)-2-(3-Azido-2-oxo-1-azetidinyl)-2-(4-acetoxyphenyl)acetic Acid 4-Nitrobenzyl Ester (8+9)

1,3,5-Tris-[D(-)-1-(4-nitrobenzyloxycarbonyl) -1-(4-acetoxyphenyl) methyl] perhydro-1,3,5-triazine [10] (1.95 g) was dissolved in $45 \mathrm{ml}$ of dry methylene chloride and $0.55 \mathrm{ml}$ of boron trifluoride etherate was added under strictly anhydrous conditions. After stirring at room temperature for 20 minutes, the mixture was cooled to $-40^{\circ} \mathrm{C}$ and $0.55 \mathrm{~g}$ azidoacetyl chloride ${ }^{8)}$ in $5 \mathrm{ml}$ methylene chloride was added under nitrogen over 25 minutes, followed by a solution of $0.76 \mathrm{ml}$ pyridine in $5 \mathrm{ml}$ methylene chloride over 25 minutes. An orange precipitate formed. After stirring for 60 minutes at $-40^{\circ} \mathrm{C}$ and for 100 minutes at $0 \sim 5^{\circ} \mathrm{C}$, the reaction mixture was washed with $1 \mathrm{~N}$ hydrochloric acid, aqueous sodium bicarbonate, water, and saturated sodium chloride.

The organic layer was dried over magnesium sulfate and evaporated to give $2.3 \mathrm{~g}$ of a $\tan$ foam. Purification by Waters HPLC on silica gel (hexane - ethyl acetate, 2:1) afforded $0.7 \mathrm{~g}$ $(29 \%)$ of a colorless oil. $[\alpha]_{\mathrm{D}}^{23}-44^{\circ}(c) 0.28$,

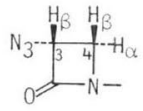

I

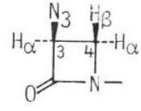

II 
$\left.\mathrm{CHCl}_{3}+\mathrm{CH}_{3} \mathrm{OH}\right):$ IR (neat, $\left.\mathrm{cm}^{-1}\right)$ 2100, 1782, 1751: NMR $\left(\mathrm{CDCl}_{3}\right) \delta 2.32\left(3 \mathrm{H}, \mathrm{s}, \mathrm{OC}^{-} \mathrm{CH}_{3}\right), 3.04$ $\left(4 \beta_{I I} \mathrm{H}, \mathrm{dd}, J=2\right.$ and $\left.5 \mathrm{~Hz}\right), 3.48\left(4 \beta_{\mathrm{I}}, \mathrm{t}, J=5 \mathrm{~Hz}\right), 3.62\left(4 \alpha_{\mathrm{I}}, \mathrm{H}, \mathrm{dd}, J=2\right.$ and $\left.5 \mathrm{~Hz}\right), 3.92\left(4 \alpha_{\mathrm{II}}, \mathrm{H}, \mathrm{t}\right.$, $J=5 \mathrm{~Hz}), 4.56\left(3 \beta_{\mathrm{I}} \mathrm{H}, \mathrm{dd}, J=2\right.$ and $\left.5 \mathrm{~Hz}\right), 4.74\left(3 \alpha_{\mathrm{II}} \mathrm{H}, \mathrm{dd}, J=2\right.$ and $\left.5 \mathrm{~Hz}\right), 5.30\left(2 \mathrm{H}, \mathrm{s}, \mathrm{OCH}_{2}-\right), 5.60$ $\left(1 \mathrm{H}, \mathrm{s}, \mathrm{H}-\mathrm{C}_{\mathrm{I}}-\right), 7.2(6 \mathrm{H}, \mathrm{m}, A r), 8.18(2 \mathrm{H}, \mathrm{d}, J=8 \mathrm{~Hz}, A r)$. Integration shows the mixture is composed of two parts of diastereomer II to one part of diastereomer I.

Anal. Calcd. for $\mathrm{C}_{20} \mathrm{H}_{17} \mathrm{~N}_{5} \mathrm{O}_{7}$ : C 54.67, $\mathrm{H} 3.90, \mathrm{~N} 15.94$.

Found: $\quad$ C 54.68, H 4.21, N 15.99 .

D-2-(3-Amino-2-oxo-1-azetidinyl)-2-(4-acetoxyphenyl)acetic Acid p-Nitrobenzyl Ester (10)

Hydrogen sulfide was bubbled into an ice cold solution of the azido $\beta$-lactams (8 \& 9) (2 g) and triethylamine $(0.64 \mathrm{ml}, 4.0 \mathrm{ml})$ in $120 \mathrm{ml}$ of methylene chloride for 15 minutes. The solution was stirred at room temperature for 1.5 hours then nitrogen was bubbled through the solution for 10 minutes. Evaporation at reduced pressure gave an oil which was redissolved in methylene chloride and again evaporated at reduced pressure. The latter procedure was repeated and the resulting oil was used directly in the next step.

3,3-Dibenzyl-p-nitrobenzyl 3-[2-[p-(3-Carboxy-3-carboxyaminopropoxy) phenyl] glyoxylamido]- $\alpha$ ( $p$-acetoxyphenyl)-2-oxo-1-azetidineacetic Acid (11)

A solution of the side chain acid (4) (2.0 g) the aminonocardicinic acid derivative described above and EEDQ $(1.1 \mathrm{~g})$ in $125 \mathrm{ml}$ of methylene chloride was allowed to stand at room temperature overnight. The solution was extracted with cold $1 \mathrm{~N}$ hydrochloric acid, water, saturated sodium bicarbonate solution, water, and brine then dried over magnesium sulfate. The solvent was removed at reduced pressure and the resulting oil was chromatographed on $200 \mathrm{~g}$ of silica gel using methylene chloride $5 \%$ acetone to afford $3.2 \mathrm{~g}(90 \%)$ of a glass-like solid.

Anal. Calcd. for $\mathrm{C}_{47} \mathrm{H}_{42} \mathrm{~N}_{4} \mathrm{O}_{14}$ : C 63.65, $\mathrm{H} 4.77, \mathrm{~N} 6.32$.
Found:
C 63.11, H 4.51, N 6.28.

3,3-Dibenzyl-p-nitrobenzyl 3-[2-[p-(3-carboxy-3-carboxyaminopropoxy) phenyl] glyoxylamido]- $\alpha$ ( $p$-hydroxyphenyl)-2-oxo-1-acetidineacetic Acid, 2' Oxime (12)

A solution of compound 11 and $1.0 \mathrm{~g}$ of hydroxylamine hydrochloride in $30 \mathrm{ml}$ of ethanol and $30 \mathrm{ml}$ of pyridine was heated at $60^{\circ} \mathrm{C}$ for 2.5 hours. The mixture was cooled and $100 \mathrm{ml}$ of methylene chloride added. The resulting solution was extracted with two aliquots of $1 \mathrm{~N}$ hydrochloric acid, water, and brine then dried over magnesium sulfate. Removal of the solvent left a glass; yield $2.2 \mathrm{~g} \mathrm{(100 \% ):} \mathrm{The} \mathrm{proton}$ magnetic resonance spectrum of this compound was similar to compound $\mathbf{1 1}$ except the acetyl was no longer present.

Anal. Calcd. for $\mathrm{C}_{45} \mathrm{H}_{41} \mathrm{~N}_{5} \mathrm{O}_{13}$ : C 62.86, $\mathrm{H} 4.81, \mathrm{~N} 8.14$. Found: C $62.91, \mathrm{H} 4.84, \mathrm{~N} 8.08$.

Nocardicin A and B (13 \& 14)

The protected nocardicin derivative $12(1.1 \mathrm{~g})$ was dissolved in a solution of $20 \mathrm{ml}$ of methanol, $10 \mathrm{ml}$ of tetrahydrofuran and $10 \mathrm{ml}$ of water. Palladium on carbon $(10 \%)(0.6 \mathrm{~g})$ was added and the mixture was hydrogenated at atmospheric pressure for 2 hours. An additional $0.3 \mathrm{~g}$ of $10 \%$ palladium on carbon was added and hydrogenation was continued for another 0.5 hour. The catalyst was filtered and the filtrate evaporated to dryness and the resulting solid was dissolved in a solution of $10 \mathrm{ml}$ of water and $5 \mathrm{ml}$ of methanol by adding $1 \mathrm{~N}$ sodium hydroxide to $\mathrm{pH}$. The solution was treated with decolorizing carbon, filtered and the filtrate was adjusted to $\mathrm{pH} 3.5$ with $4 \mathrm{~N} \mathrm{HCl}$. The resulting solid was collected and dried to afford $0.25 \mathrm{~g}(39 \%)$. Proton magnetic resonance spectroscopy indicated that this material contained both nocardicin A and B with the former as the major product. Bioassay showed about $25 \%$ of the potency of an authentic sample of nocardicin A (see Table 1).

Anal. Calcd. for $\mathrm{C}_{23} \mathrm{H}_{24} \mathrm{~N}_{4} \mathrm{O}_{9} \cdot \mathrm{H}_{2} \mathrm{O}$ : C 53.28, $\mathrm{H}$ 5.05, N 10.81 .

Found:

C $53.13, \mathrm{H} 4.95, \mathrm{~N} 10.61$.

Acknowledgement

We wish to thank Dr. William Gore and his staff for the spectral data and Mr. Louis BranCone and staff 
for the microanalysis reported herein. Special thanks are due to Mr. George Morton for his aid in interpretation of the NMR spectra. We also thank Mrs. N. KUCK and staff for the bioassays included in this report.

\section{References}

1) Aoki, H.; H. Sakai, M. Kohsaka, T. Konomi, J. Hosoda, T. Kubochi, E. Iguchi \& H. Imanaka: Nocardicin A, a new monocyclic $\beta$-lactam antibiotic. I. Discovery, isolation and characterization. J. Antibiotics 29: 492 500, 1976

2) Hashimoto, M.; T. Komori \& T. KamiYA: Nocardicin A, a new monocyclic $\beta$-lactam antibiotic. II. Structure determination of nocardicins A and B. J. Antibiotics 29: 890 901, 1976

3) Koppel, G. A.; L. McShane, F. Jose \& R. D. G. Cooper: Total synthesis of nocardicin A. Synthesis of 3-ANA and nocardicin A. J. Amer. Chem. Soc. 100: 3933 3935, 1978

4) KamiYa, T.; M. Нashimoto, O. Nakaguchi \& T. OkU: Total synthesis of monocyclic $\beta$-lactam antibiotics, nocardicin A \& D. Tetrahedron 35: 323 328, 1979

5) Hakimelaki, G. H. \& G. Just: $\beta$-Lactams. V. The synthesis of D,L-4-hydroxymethylnocardicin A, D,Lhydroxymethyl- $N$-phenylacetylnocardicinic acid and their $\alpha$-epimers. Can. J. Chem. 57: 1932 1938, 1979

6) Chang, C.D. \& J. K. Coward: Analogues of 5-adenosylhomocysteine as potential inhibitors of biological transmethylation. Synthesis of analogues with modifications at the $5^{\prime}$-thioether linkage. J. Med. Chem. 19: $684 \sim 691,1976$

7) Barnish, J. T.; P. E. Cross, J. C. Danilewicz, R. P. Dickinson \& D. G. Stapher: Promotion of carbohydrate oxidation in the heart by some phenylglyoxylic acids. J. Med. Chem. 24: 399 404, 1981

8) Bose, A. K.; B. Anjaneyulu, S. K. Bhattacharya \& M. S. Manhas: Studies on lactams. V. 3-Azido2-azetidinones. Tetrahedron 23: 4769 4776, 1967

9) KamiYa, T.; T. OKu, O. Nakaguchi, H. Takeno \& M. Hashimoto: A novel synthesis of nocardicins and their analogues. Tetrahed. Lett. 1978: 5119 51221978 